\title{
AC 2007-386: EXPECTING THE UNEXPECTED AS AN EXPECTING FACULTY MEMBER: A QUALITATIVE STUDY
}

Adrienne Minerick, Mississippi State University

Mara Wasburn, Purdue University

Valarie young, Ohio University 


\title{
Expecting the Unexpected as an Expecting Faculty Member: A Qualitative Study
}

\author{
Adrienne R. Minerick', Mara H. Wasburn' ${ }^{1}$, Valerie L. Young ${ }^{3}$ \\ ${ }^{1}$ Dave C. Swalm School of Chemical Engineering \\ Mississippi State University \\ Mississippi State, MS 39672 \\ I \\ ${ }^{2}$ College of Technology \\ Purdue University \\ West Lafayette, IN 47907 \\ / \\ ${ }^{3}$ Department of Chemical and Biomolecular Engineering \\ Ohio University \\ Athens, OH 45701
}

\begin{abstract}
Increasingly, women are having or caring for children while in tenure-track faculty positions. This paper focuses on the experiences of pregnant engineering faculty members, using qualitative data derived from a survey of women faculty who are members of the American Society for Engineering Education Women in Engineering Division and their colleagues. Although each woman's experience as an expectant faculty member is different, some commonalities exist and are discussed in this paper. This information may 1) assist academic departments, particularly those that have historically been male-dominated, in supporting and retaining their women faculty members during and after childbearing and 2) help women be informed of successes, challenges and solutions.
\end{abstract}

\section{Introduction}

Women have made great progress in academe. Yet while there are more women assistant professors than ever, relatively few of them become full professors ${ }^{1}$. As more women are entering tenure-track engineering and technology faculty positions during their childbearing years, issues surrounding faculty pregnancy have become increasingly relevant. Many universities have made significant progress updating their tenure policies to accommodate challenges encountered during maternity and parental leaves. However, the research described below indicates that women faculty seeking advancement, especially those in science, technology, engineering, and mathematics (STEM), continue to face impediments that do not appear to equally impede their male counterparts. These impediments were well-documented by research in the 1970s and 1980s. Women faculty who choose to have babies early in their careers are still less likely to achieve tenure than their male counterparts ${ }^{2}$.

This paper is divided into five main sections. First is a review of the literature on women in academe, focusing particularly on those with children. Second is a summary of the demographics of the survey respondents. Third is a discussion of institutional support, which provides an overview of the variety of policies reported in the survey. The fourth section is a discussion of 
perceptions of this support. Finally, we will discuss solutions and successes based upon the literature and experiences of the survey respondents. We note that two of the authors were themselves pregnant prior to achieving tenure, and their experiences and perceptions are included.

\section{Women in Academe}

In the 1980s, Hall and Sandler ${ }^{3}$ observed that the source of women's relative lack of representation in high-level academic and faculty positions on college campuses, was rooted in their higher education experience. They coined the now-famous term "chilly classroom climate" to refer to the effects that male-dominated university campuses have on undergraduate women. They argued that male professors' use of sexist humor, belittling albeit bantering comments about women's intellectual abilities, and their use of "he" to refer to scholars in their fields can considerably dampen women's career aspirations. Almost twenty years later, Martin ${ }^{4}$ asserted that the campus climate remained chilly, resulting in "an under-representation of women in the highest ranks of the profession" (p. 85).

In the STEM disciplines, women faculty describe a "null environment for women" where they often receive less support and colleagueship. Often the only or one of very few women in their departments, they frequently are not part of the camaraderie that develops among the younger faculty, resulting in lack of access to information and opportunities. The cumulative effect of this bias causes a number of women to leave academia ${ }^{5}$

Research reveals that women faculty describe greater isolation, less time for research, greater teaching loads, more committee assignments, fewer mentors, and more trivializing of their scholarship than their male colleagues do. ${ }^{6,7,8,9,10}$ Rosser $^{11}$ observes that the overwhelmingly male nature of STEM disciplines has not only afforded women limited access to participation, but it has shaped the very nature of the discipline itself. She observes that science, for example, is neither unbiased nor value-free. Everything from what is studied to the subjects for the experiments is male-dominated. It is her contention that when women enter a field, different questions are asked and methodological and theoretical assumptions challenged (p. 84.) These challenges can lead to the trivializing of their scholarship noted above.

The bar for gaining promotion and tenure is rising steadily. With most departments at research and teaching institutions demanding more published research, there is now greater pressure on new faculty to publish early and often. ${ }^{12,13,14}$ This adds considerably to the already existing challenges women faculty face. They are often advised to publish more and devote less time to teaching and service activities. ${ }^{15}$ However, as institutions grow more concerned about diversity, women, as well as minority faculty, are more likely to be asked to devote time to teaching and service activities. Many believe they have a special responsibility to advise women and minority students, often at the expense of their own need to publish, creating "a possible mismatch between institutional demands and the perspectives of women and minority faculty members" ${ }^{16}$. Spending a disproportionate time being "good citizens" can result in fewer publications, further damaging women's opportunities for promotion. ${ }^{17,18}$ By contrast, male academics tend to invest more of their time and energy in research and publication. Since salary and promotion are tied to research and publications, women fall farther and farther behind. The higher the rank, the lower the proportion of women, especially in the STEM disciplines. ${ }^{19}$ 
Compounding the problems of women faculty is the fact that they often receive little respect in the classroom, especially those in the STEM disciplines where women have been historically underrepresented. ${ }^{20}$ Female professors are expected to be warm and nurturing. But when they are, they can be perceived as weak. If they are more assertive, they are viewed as being too demanding, unapproachable, with standards that are not in line with norms.

The Impact of Motherhood in Academe

Women with children face special challenges. The competing expectations of career and motherhood can produce a type of stress that their male counterparts who either take a secondary role in childrearing or who are not parents at all rarely if ever experience. ${ }^{21}$ A 2006 study of 1,755 employed parents revealed a substantial loss of productivity due to childcare concerns. ${ }^{22}$ In academe, since tenure and promotion decisions are usually made during the childbearing years, these competing claims can be devastating. Although many universities have policies that can slow the tenure clock for women, work in the mid-1990's showed that very few of them actually take parental leave for fear that their senior colleagues will hold it against them. ${ }^{23,24}$

While childbearing has received some attention in the form of policies designed to assist women professors, little if any attention has been paid to the effects of child rearing. ${ }^{25}$ Significantly more men than women with children under the age of six achieve tenure. Many women assistant professors are cognizant of this additional disadvantage and are choosing to postpone having children. Almost half of them say the decision was made because of their careers. A 2006 survey of 4,400 ladder rank faculty found that 40 percent of women said they had fewer children than they wanted, compared to 20 percent of men. ${ }^{26}$

Joan Williams, a professor of law at American University's Washington College of Law refers to these challenges as the "maternal wall, a less obvious form of gender discrimination than the more familiar glass ceiling. It begins when women become pregnant. The assumption is made that they will only want to work [or are only capable of working] part time. Being a caregiver and an academic are seen as incompatible.",27

\section{The Critical Need for Supporting Women STEM Faculty}

In July 2005, fifteen major American business groups, led by the Business Roundtable, issued a joint statement about the declining prominence of the United States in STEM fields. The statement called for the nation to double the number of college graduates in those fields by 2015 . Data from their research indicated that more than 50 percent of the current United States science and engineering workforce is approaching retirement age and that by 2010 , if present trends continue, most of the world's scientists and engineers will be living in Asia. The report further stated that the scientific and technical capacity of the United States has already begun to shrink, which is a threat to America's standard of living at home and leadership in the world. ${ }^{28}$

Approximately half the potential STEM talent pool at the entering undergraduate level consists of women. Therefore, in 2000, a United States government commission was charged with developing strategies to attract more women and minorities in STEM careers. The commission reported to the Committee on Science of the House of Representatives that significant barriers to these goals persist. ${ }^{29}$ These deterrents range from differing male/female attitudes toward science 
and technology that begin to diverge as early as elementary and middle school, to the absence of women faculty, mentors, and fellow students in college and university classrooms that create a "chilly climate for women" in these areas ${ }^{30,31}$

There are numerous career opportunities for women in information technology. However, in spite of these opportunities, there has been a steady decline in the number of computer science bachelor's degrees awarded, particularly to women. ${ }^{32}$ In 1983-84, more than 37 percent of the bachelor's degrees in computer science were awarded to women. Ten years later, the percentage had fallen to 28 percent, and it has held relatively steady through the new millennium. ${ }^{33}$

Research on women in computer science revealed that the emphasis at the post-secondary level is on the social psychological factors that prevent women's inclusion. ${ }^{34}$ Margolis and Fisher ${ }^{35}$ used the metaphors of a "clubhouse" to describe the extent to which women are excluded from the male purview of computing, and "dreaming in code" as "emblematic of a male standard of behavior in this computer-oriented world." The authors no longer want to try to fit women into this male culture. They issued a call to arms for a revolution in the culture and curriculum of computer science that will encompass and respect the contributions that women can make to the discipline.

As young women grow older, fewer of them express interest in studying STEM subjects. The literature refers to a "leaky" pipeline of women from elementary school through graduate studies and employment, eventually leading to their under-representation in the STEM professions. ${ }^{36}$

If we are to have faculty prepared to educate the new generation of engineers and technology professionals, we must make encourage and support all faculty, paying particular attention to those groups most likely to leave before attaining tenure. Below are the results of a survey of women faculty who have faced the challenges of being mothers and mothers-to be while working toward promotion and tenure.

\section{Survey Respondent Demographics}

A survey comprised of 7 multiple choice questions, 1 short answer question, and 1 essay question was distributed via e-mail and the World Wide Web (using "Survey Monkey") to Women in Engineering Division members of ASEE and their colleagues. Since the number of women in a particular department, college, or school of engineering is often small, employer names were not collected in order to protect respondents' anonymity, and it is not possible to determine how many colleges and universities are represented. The IRB offices at Mississippi State University, Ohio University, and Purdue University approved the survey. The survey was open for one week, during which women faculty responded rapidly, suggesting that this is an issue that women faculty consider to be of great importance. A total of 103 people responded to the survey. Respondents were able to skip any question they chose, so total respondents on each question varied slightly. These numbers are noted alongside discussion of each question's response results.

The first multiple choice question sought to determine what pregnancy or childcare situation the respondent had experienced. Respondents were able to choose all the situations that applied to them; responses are summarized in Figure 1. Note that being pregnant and having preschool- 
aged children are not mutually exclusive options, suggesting that 6 respondents had their children shortly before entering a tenure-track position. The number of respondents who were pregnant or with preschool-aged children prior to attaining full professor is smaller than the number in these situations prior to attaining tenure. These numbers fail to elucidate the number of associate professors who have been raising children and will not attain the rank of full professor (a point that was highlighted repeatedly in the open essay question). The majority of the survey respondents were pregnant or had pre-school age children in the last 5 years (60 of 102 responses), while only 8 of 102 respondents were in this situation more than 20 years ago. Many factors can be responsible for this distribution including that a) many more women are choosing academic careers than did 20 years ago, b) the response rate was greater for those most recently in this position, or c) that more women faculty now choose to have children along with their careers.

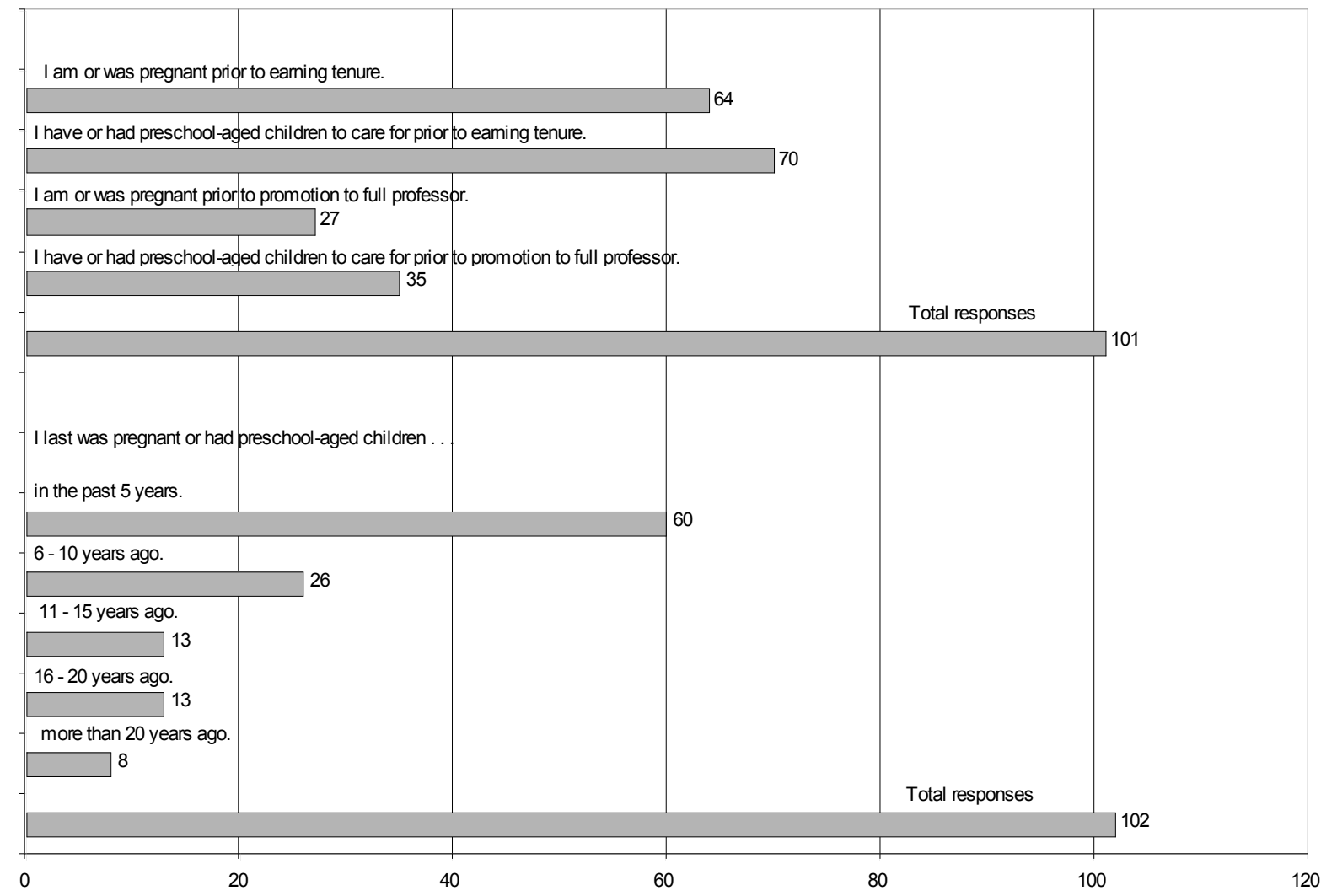

Figure 1. Type and timing of pregnancy and childcare situations for respondents

Most respondents were at a doctoral granting institution when they were pregnant and/or had pre-school age children (74 of 99 respondents). Ten and fourteen respondents were at Master's and Bachelor's granting institutions, respectively. Only one community college professor responded to the survey. The majority of respondents (84 of 99) were in an engineering department while 11 and 4 were in technology or other physical and natural science departments, respectively.

In order to probe proximity issues, the survey asked for the number and rank of female colleagues in the respondent's department. Figures varied between 0 and 9 female colleagues. 
Respondents had on average about 2 female colleagues in their department; these colleagues were identified as predominantly assistant professors.

\section{Institutional Support}

Respondents were asked via two multiple choice questions what institutional support was available to them (paid parental leave, unpaid parental leave, stopping your tenure clock, or other) and then were asked to rate their perception / experiences regarding institutional, departmental, and collegial support they received as an untenured faculty member during pregnancy/pregnancies or with an infant and/or preschool age child/children to care for.

A majority of respondents, $54 \%$ or 50 of 92 total responses to this question, chose 'other' and described a variety of modified teaching responsibilities. 31 indicated that paid parental leave was available while 26 indicated unpaid parental leave was available to them. $46.7 \%$ or 43 of the 92 respondents indicated that stoppage of their tenure clock was an option, although many of the comments indicated that women were wary of exercising this option because of concerns on how it would be perceived by their senior colleagues or in the greater professional arena.

When respondents were asked to rate their perception and experiences regarding this support, the results were distributed evenly around 'adequate', which seemed at odds with comments made in the open-ended essay question. These comments are discussed in the next section. A total of 93 individuals rated their perceptions of support on the 5-point scale (excellent $=14$, good $=24$, adequate $=27$, fair $=17$, poor $=11$ ), while 88 responded to the essay question. Many respondents who rated the overall support as adequate or better on the 5-point scale described negative experiences in the essay. Often, these respondents also described particularly positive elements of their immediate professional environment, such as supportive colleagues or chairs.

\section{Perceptions of Support}

Further information was gathered via the one essay question. A few testimonials are highlighted here; direct quotes are offset in italics.

One described the climate of active hostility that she experienced $16-20$ years ago. "Before my children were born, I was asked to submit a letter of resignation with the understanding that it would be used if I did not come back to work promptly." A response describing a situation 10 years ago also appears hostile, though more by neglect than by action. "My department chair failed to find a replacement for me for the term in which I was due to give birth. I was assigned to teach a full load of courses (4 hours of lecture and 16 hours of lab per week). . . [I increased] my weekly contact hours to 20 so that the lecture portion of my courses would be completed by [my due date]. I recruited a replacement for me in the lab-and hiring was completed 2 days before I delivered. . . I had to secretly come into the lab to assist this person for the rest of the term. . . the HR department at my University would not allow me to be on campus due to my 'disability'." From a faculty member whose child was born within the past five years: "I received no support - had only a week and a half leave and had to go back to teaching my class. Nobody offered to give me a break from teaching or anything else throughout pregnancy, immediately after delivery and during the time my daughter was an infant." Most responses evoke something that respondents describe "as 'benign neglect' - not hostile, but not 
actively helpful either." This lack of open communication can also manifest itself in other ways. "Older men in my department who had stay at home wives tried (in their own way) to be helpful. They excluded me from committee emails, faculty policy discussions, etc. because they 'were trying to protect me'. I found it patriarchal because it suggested I was no longer capable of making my own decisions." The support a faculty member receives is highly dependent on the environment in her department and college. "I have one semester of teaching relief and there is no institutional rule on what to do. We must depend on the mercy of our College. In my case, the College is supportive with the teaching relief, but this may not be so throughout the university."

Many respondents cited confusion about the policies at their institution, sometimes on their part, sometimes on the part of the administration. At one respondent's institution, the faculty governing council proposed a policy for faculty family medical leave in 2006, because the existing policy applied only to staff. In spite of this, the respondent had requested and been granted family medical leave for her most recent pregnancy in 2004; she and her chair assumed the policy applied to all university employees. Confusion about policy is stressful because of its impact on career decisions. "I wasn't sure if I took the [term] off teaching if I would be allowed to go up for tenure since there is a requirement on the number of semesters taught, and I got conflicting advice on this." Confusion can be a trigger for resentment from colleagues. "Nearly all faculty in my department thought I was getting special treatment when I took advantage of parental leave that is available to EVERYONE." Institutional maternity leave policies that do not take into account that faculty contracts sometimes cover fewer than 12 months are also a problem. "[There is no] paid summer maternity leave, because we're on 10 month contracts with summer research support."

Many women described a negotiated concession in their teaching schedule. The option to stop the tenure clock is officially widely available, and perhaps the most realistic relief a new parent can expect from research responsibilities. However, women often feel discouraged from using this option, or any type of maternity leave. Many believe that a gap in their professional credentials will still be viewed unfavorably, or that an extension will be viewed as extra time that should result in greater productivity. For example, all respondents who negotiated teaching concessions "paid back" their temporary reduced teaching loads with increased teaching in another term. Similarly, "[My] research and teaching programs remained largely unaffected, but I found that the timing and number of [my] publications was severely affected. Hopefully, the extension of the tenure clock will help strengthen the publication record, but I am concerned about the increase in expectation due to the extension of the tenure clock even though it is technically a non-issue on paper."

An area that was frequently overlooked by the institution was the availability of reliable childcare as soon after childbirth as the faculty member desires. It seems it would be to the institution's advantage to make this available sooner so that the faculty member can remain productive throughout this period if they so choose. At the very least, a guaranteed position in any university sponsored childcare by the end of the approved paid leave period seems appropriate. Essay responses described extremely long waiting lists for university daycare, and the difficulty of obtaining quality daycare that allows flexibility in pickup or dropoff times. 
One key distinction that should be made is although official policies can be quite supportive of women faculty with child(ren), colleague's reactions or informal responses to the situation can create climates (either transient or engrained) that are not friendly. It only takes one individual to promote an adverse climate or to place unnecessary pressure on a faculty member in this situation. If that negative individual is senior or serving on a promotion and tenure committee, pressure on the expecting or childrearing faculty member is greater. Department heads, by nature of holding a leadership position, have a greater influence on perceptions of a faculty pregnancy. One woman reported, "I was initially left off of faculty lists and my department head publicly made the comment that they were shorthanded for a year (comment resulting from the dept. head's lack of understanding of the one-year delay of tenure)." Another respondent said, "A professor from another department who was on the college P\&T committee told me directly that faculty members do not have children and he was annoyed that family leave was even a topic of discussion for [the university]." Conversely, a supportive environment in the department can lead a faculty member to rate her experience as positive overall, in spite of challenges.

Women were also asked whether their timing for having children was influenced by promotion / tenure concerns. $43 \%$ (42 of 98 responses) indicated that this was in fact a concern, but this was outweighed slightly by the 56 who did not take this into consideration. In the essay, several respondents described feeling to various degrees that they had to choose between career success and family. "I have always felt that I was forced to make a decision whether to compromise family or success. I elected that the compromise would come mostly out of career success....However, I recognize that I made these choices (to attempt to have both career and family), and whatever compromises have to be made are part of the package. This is not to say that I am not resentful of the clear gender bias there is regarding such compromises. A very significant fraction of the faculty in my department have stay-at-home wives. All those with young children do."

The idea that academic life often assumes that a faculty member has a stay-at-home spouse frequently surfaced in the comments. "I am competing with men who have wives that stay at home. They can work late any night they want without consequence. I have to schedule late nights way in advance, or skip them altogether." Similarly, "My lack of participation at night events or weekend events (recruiting, professional dinners) has been noted...I do not think this is unique to my university, but an indication that the academic culture still revolves around male norms and practices." Several respondents noted that this was a concern for both members of a dual-career couple, not just women. However, it impacts women disproportionately because women faculty are more likely than their male counterparts to be married to professionals who work outside the home. Respondents noted several positive steps that institutions can take to alleviate this. Popular ones included not scheduling parents of young children to teach at 8:00 am, and scheduling most meetings between the hours of 9:00 and 5:00. Several respondents also noted positively the informal network of colleagues, male and female, who cover classes and meetings for one another when unexpected childcare issues arise. Many respondents specifically noted their willingness to work at home outside regular work hours; it is the expectation that one can easily appear in person that is objectionable.

"I've had preschoolers and/or been pregnant for all but the last few years of my 20 years teaching. The only way it's worked for me is that I've had awesome department chairs and 
colleagues.... Also, when I went up for tenure (10+ years ago), I based my case on excellence in teaching and didn't need funded research. Now I'm a full professor sitting on the P\&T committee; I don't see how any woman can juggle teaching, funded research, and a family, unless she has dependable, full time help - and is involved with her children no more than my father was involved with me..."

\section{Recommendations and Conclusion}

Overall, official institutional support appears sufficient, although many find inconsistencies in interpretations and versions of written policies. It would be advisable for institutions to develop a faculty family leave policy that accounts for unusual features of faculty life, such as academic year contracts with full-year expectations for productivity. The policy should be readily accessible, and discussed in orientation of new or interim department heads as well as refresher meetings for long standing department heads. Several respondents mentioned that stopping the tenure clock in cases of family or medical leave was now automatic at their institution. Presumably, this removes some of the potential stigma for doing so. So long as the faculty member has the option to request early review, such a policy would present no obvious disadvantages.

Quite apart from official institutional policies, it is clear that individual colleges and departments control the perceived environment for faculty members starting and raising families. The department or college can build a remarkably supportive environment where no official policy exists, or can follow the letter of an official policy while destroying its spirit. Key steps that are often under local control include preferentially scheduling meetings between 9:00 and 5:00, expecting personal appearances at nights and on weekends only with advance notice, and offering parents of young families the option not to teach at 8:00 am. Willingness to cover for one another in unexpected situations builds a positive atmosphere. Such steps create a supportive environment for faculty parents regardless of gender.

Furthermore, the community of women faculty either considering children or who are or have raised children would benefit greatly from a mentoring network. Several respondents talked about being "first in my college" or about "having no idea what this would entail". Having a network within and beyond one's university could be helpful in determining best coping strategies for balancing family life and career success.

\section{References}

1. Women in Engineering Programs and Advocates Network (WEPAN). Statistics compiled by CPST (www.cpst.org). Copyrighted slides 2006.

2. Wilson, R. (2005) Rigid Tenure System Hurts Young Professors and Women, University Officials Say. The Chronicle of Higher Education.

3. Hall, R.M., \& Sandler, B.R. (1982). The classroom climate: A chilly one for women. Washington, DC: Association of American Colleges.

4. Martin, J.R. (2000). Coming of age in academe. New York: Routledge.

5. Betz, Nancy E. 1992. The invisible woman: Effects of the educational environment on women's Vocational identity. In Women's work, edited by Smith, Nancy J., and Sylvia Leduc. Calgary, AB: Detselig Enterprises, Ltd.

6. Johnsrud, L.K. \& Des Jarlais, C.D. (1994). Barriers to tenure for women and minorities. The Review of Higher Education, 17, 335-353. 
7. Blakemore J. E., S witzer, J.Y., D ilorio, J.A., \& F airchild, D.L. (1997) Exploring the campus climate for women faculty, in: N. V. Benokraitis (Ed) Subtle Sexism: Current Practice and Prospects for Change. Thousand Oaks, CA: Sage Publications.

8. Creamer, E. G. (1995) The scholarly productivity of women academics, Initiatives, 57, -9.

9. Glazer-Raymo, J. (1999) Shattering the Myths: Women in Academe Baltimore, MD: The Johns Hopkins University Press.

10. Tierney, W. G., \& Bensimon, E. M. (1996) Community and Socialization in Academe. Albany: State University of New York Press.

11. Rosser, S. V. (1997). Re-engineering female friendly science. New York: Teachers College Press.

12. Jacobs, J., \& Winslow, S. (2004) Overworked faculty: job stresses and family demands, The Annals of the American Academy of Political and Social Sciences, 596, 104-129.

13. Valian, V. (1999). Why so slow? The advancement of women. Cambridge, MA: The MIT Press.

14. Wilson, R. (2001, January 5) A higher bar for earning tenure, The Chronicle of Higher Education, A12.

15. Park, S.M. (1996). Research, teaching and service: Why shouldn't women's work count? Journal of Higher Education, 64, 46-84.

16. Allen, Helen. 1994. Workload and productivity in an accountability era. 1994 Almanac of Higher Education: $25-38$

17. Creamer, E.G. (1995). The scholarly productivity of women academics. Initiatives, 57 (1), 1-9.

18. Astin, H.W., \& Bayer, A.E. (1973). Sex discrimination in academe. In Rossi, A.S., \& Calderwood, A. (Eds.) Academic women on the move. New York: Russell Sage Foundation.

19. Fox, M. F. (1996). Women, academia, and careers in science and engineering. In Davis, C. et al. (Eds.), The equity equation: Fostering the advancement of women in the sciences, mathematics, and engineering. (pp. 96-121). San Francisco: Jossey-Bass.

20. Sandler, B.R. (1991). Women faculty at work in the classroom, or why it still hurts to be a woman in labor. Communication Education, 40, 6-15.

21. Williams, J. (1999). Unbending gender: Why family and work conflict and what to do about it. New York: Oxford University Press.

22. Catalyst. (2006). After school worries. New York: Catalyst Press.

23. Finkel, S.K., Olswang, S., \& She, N. (1994). Childbirth, tenure, and promotion for women faculty. 8 The Review of Higher Education, 17, 259-270.

24. Wilson, R. (1995, March 10). Scheduling motherhood. The Chronicle of Higher Education. A14-A15.

25. Finkel, S.K., \& Olswang, S. G. (1996). Child rearing as a career impediment to women assistant professors. The Review of Higher Education, 19, 123-129.

26. Mason, M. A., \& Goulden, M. (2004). Annals of the American Academy of Political and Social Science, $596(1), 86-103$.

27. Santovec, M. L. Tips to change the culture and breach the 'Maternal Wall. (2005). Women in Higher Education, 14 (7), 20-21.

28. Business Roundtable. (2005). Tapping America's potential Retrieved January 10, 2007, from http://www.businessroundtable.org/pdf/20050803001TAPfinalnb.pdf.

29. Committee on Science. House of Representatives. (2000), A review of the Morella Commission report recommendations to attract more women and minorities into science, engineering, and technology, Serial No. 106-83. Washington, DC: U.S. Government Printing Office.

30. AAUW. (2000). Tech-Savvy:Educating girls in the new computer age. Washington, DC: AAUW Educational Foundation.

31. Seymour, E. (1999) The role of socialization in shaping the career-related choices of undergraduate women in science, mathematics, and engineering majors. Annals of the New York Academy of Sciences, 869, 118126.

32. Camp, T. (1997). The incredible shrinking pipeline. Communications of the ACM, 40 10), $103-110$.

33. Camp, T. (2002). Forward to women and computing. SIGSE Bulletin, 34 (2), 1-6.

34. Dryburgh, H. (2000). Underrepresentation of girls and women in computer science: classification of $1990 \mathrm{~s}$ research. Journal of Educational Computing Research, 23(2), 181-202

35. Margolis, J., \& Fisher, A. (2000). Unlocking the clubhouse: Women in computing. Cambridge, MA: MIT Press.

36. Freeman, C. E. (2004). Trends in educational equity of girls \& women: 2004 (No. NCES 2005-016). Washington, DC: U.S. Government Printing Office: U.S. Department of Education, National Center for Education Statistics. 


\begin{abstract}
ADRIENNE R. MINERICK
Adrienne Minerick is an Assistant Professor of Chemical Engineering at Mississippi State University. She received her PhD from the University of Notre Dame in August 2003. Adrienne teaches the required graduate ChE math, process controls, and helps with the Introduction to Chemical Engineering class. Adrienne's research is in medical microdevice diagnostics and dielectrophoresis. She is active in ASEE.
\end{abstract}

MARA H. WASBURN

Mara H. Wasburn is an Associate Professor of Organizational Leadership at Purdue University. She received her Ph.D. from Purdue University in 1998. Wasburn's research, teaching, and engagement are in the area of mentoring, with an emphasis on women in technology.

VALERIE L. YOUNG

Valerie Young is Associate Professor and Chair of Chemical and Biomolecular Engineering at Ohio University. She received her Ph.D. from Virginia Polytechnic Institute and State University in 1992, and her B.S. from Lehigh University in 1988. Valerie currently teaches four courses annually, including the required material balances and statistics courses. Her research is in air quality, tracing the sources, dispersion, and fate of atmospheric pollutants. She has a daughter born pre-tenure and a son born post-tenure. She is currently chair-elect of the Chemical Engineering division of ASEE. 